\title{
Percutaneous endoscopic debridement and irrigation for thoracic infections
}

1. Jining No.1 people's Hospital, Jining Shi, Shandong Sheng, China 2. Shandong University, Qilu Hospital, Jinan Shi, Shandong Sheng, China

\section{SUMMARY}

OBJECTIVE: To investigate the safety and efficacy of percutaneous endoscopic debridement and irrigation for thoracic infections and to make an appropriate choice according to the patient's condition.

METHODS. Thirty patients with thoracic infections who received surgical treatment from August 2014 to December 2016 were retrospectively analyzed. There were 16 males and 14 females, aged from 41 to 90 years, with an average of 64.4 years. A total of 9 cases were treated with percutaneous endoscopic debridement and irrigation (minimal group), and 21 cases were treated with open debridement in combination with pedicle screw fixation (conventional group). Patients underwent follow-up for 1 month. General condition, operative index, laboratory results, and imaging features were recorded.

RESULTS. Compared with the conventional group, there were more comorbidities in patients in the minimal group (8 cases in the minimal group, 10 cases in the conventional group, $P=0.049)$, shorter hospital stay $(10.1+2.26$ days in the minimal group, $16.1+6.81$ days in the conventional group, $P=0.016)$, less bleeding volume $(383.3+229.86 \mathrm{ml}$ in the minimal group, $90+11.18 \mathrm{ml}$ in the conventional group, $P=0.000)$, lower VAS score at discharge $(2.9+0.93$ in the minimal group, $3.9+0.91$ in the conventional group, $P=0.013)$. There was no spinal instability case in the minimal group, 10 cases in the conventional group, $P=0.013$. There were significant differences. The $C$ reaction protein prior to operation in the minimal group was $28.4 \pm 7.50 \mathrm{mg} / \mathrm{L}$. Compared with $45.1+15.78 \mathrm{mg} / \mathrm{L}$ in the conventional group, $P=0.005$, it was lower.

CONCLUSIONS. Percutaneous endoscopic debridement and irrigation are an effective surgery for treatment of thoracic infections, especially suitable for patients with comorbidities and poor general condition. However, for severe infection and spinal instability, we tend to choose open surgery in combination with fixation.

Keywords: Debridement. Endoscopy/methods. Infection.

With the aging of the population, the increase of underlying disease and immunosuppressed patients, and drug-resistant tuberculosis the incidence of spinal infections have increased ${ }^{1}$. Spinal infections include suppurative spondylitis, spinal tuberculosis, brucellosis, fungal infection, among others. It requires long treatment cycles and high costs, sometimes easily relapsing and even threatening patients' lives $^{2}$. It is something that has become a heavy burden on families and society.

Infections, especially tuberculosis, easily affect the thoracic spine. It is different from the lumbar and cervical spine. Because of its adjacent position to the pleura and thoracic cavity and reduced blood supply for the spinal cord, the thoracic spine surgery is complex and high risk. 
The purpose of the operation is the identification of pathogenic bacteria species, debridement, correction of deformity, and reconstruction. Conventional surgery involves skin incision by posterior radical debridement, decompression, and pedicle screw fixation. This approach improves the rates of inflammatory relapse, but leads to surgical trauma, blood loss, and postoperative complication.

Minimally invasive surgery can avoid these disadvantages, it includes CT guided biopsy, minimal posterolateral decompression and fusion, percutaneous discectomy, tubular retractor system, among others. It can minimize injury to body tissues, reduce bleeding volume, and shorten postoperative bed rest $^{3}$. Percutaneous endoscope for thoracic infection is rarely reported. Sometimes the thoracic spine is considered a restricted area for percutaneous endoscopic surgery. In our department, the percutaneous endoscope was used for thoracic infections, and the data was collected in order to analyze the effects of the surgery.

\section{MATERIALS AND METHODS}

\section{Demographic Data of the Patients.}

A total of 30 patients who underwent surgical treatment for thoracic infections in Qilu hospital and Jining No.1 people's hospital from August 2014 to December 2016 were retrospectively analyzed. The institutional review board of the Qilu Hospital and Jining No.1 People's Hospital approved this study, and all patients gave their informed consent. Of all patients, 16 were male, and 14 female. The age ranged from 41 to 90 years, with an average of 64.4 years. There were 7 cases of Pyogenic spondylitis, 21 cases of spinal tuberculosis, and 2 cases of brucellosis, all were thoracic infections. Patients were divided into two groups, percutaneous endoscopic debridement and irrigation group (minimal group) and open debridement and fixation group (conventional group). There were 9 cases in the minimal group, and 21 cases in the conventional group. General condition, operative index, laboratory results, and imaging features of the two groups were collected.

General condition included age, gender, smoking, comorbidity, and duration of hospital stay. Operative index consisted of bleeding volume, operation time, and preoperative, at discharge and 1-month postoperative VAS scores. The imaging features focused on abscesses, deformities, nerve deficit, and spinal insta- bility. As for laboratory results, we chose C-reactive protein and erythrocyte sedimentation rate, which reflected the severity, progression, and therapeutic effect of the disease. Tumors and rheumatisms were excluded by laboratory tests and radiological imaging. Before surgery, all patients received antibiotics, but were not relieved.

\section{Surgical Procedures.}

Minimal group: Patients were prone positioned. The entry point was marked under fluoroscopic guidance. We used local anesthesia so that the patients were aware. Usually, the puncture point was 8-9 $\mathrm{cm}$ to the midline, parallel to the target intervertebral space, and the angle was 45 degrees from the coronal plane. The puncture needle was inserted into the disc through the foramen. The working cannula was placed and was connected with the Joimax endoscopy system. Aggressive debridement was carried out to remove nucleus pulposus, inflammatory granulations, and dead bones. Pathogenic specimens were sent for laboratory examination. Routine, smear, pathological, and etiological tests were performed. Mass antibiotic saline was irrigated, inflow and outflow. After thorough hemostasis, the drain tube was placed.

Conventional group: Before surgery, a biopsy was needed to identify pathogenic types. General anesthesia was adopted, and the patient was prone positioned. A midline incision was performed, and then through the paraspinal muscle approach, the articular process was exposed. Decompression was performed bilaterally through the articular process. The lamina was preserved without nerve compression. If there was nerve deficit, compression was needed to remove the lamina and open the vertebral canal. Nucleus pulposus, inflammatory granulations, and dead bones were cleaned up, and pathogenic specimens were sent for laboratory examination. Pedicle screws and titanium cage were inserted. After saline irrigation, two drain tubes were placed.

\section{Postoperative management.}

Appropriate antibiotics were selected according to a drug sensitivity test, isoniazid and streptomycin were selected for spinal tuberculosis, and tetracycline was chosen for brucellosis. The pathogen types couldn't be identified for 2 patients, but trial antituberculous therapy was effective, so they were considered to be atypical thoracic tuberculosis. Drainage 
tubes were removed 7-10 days after surgery, and patients could practice early ambulation with the help of orthosis.

\section{Statistical analysis.}

All data was in the form of mean \pm variance or cases-percentage. The sample size of both groups was less than 30 and did not coincide with a normal distribution; a nonparametric test was used. The Mann-Whitney test was used to compare independent measurement data, the Wilcoxon test was used to compare paired measurement data, and the Fisher exact test was used to compare enumeration data. $P$ values $<0.05$ were considered statistically significant. Statistical analyses were performed using SPSS 21.0.

\section{RESULTS.}

There was no significant difference between the two groups in terms of age, gender, and smoking. Patients with comorbidities in the minimal group were $88.9 \%$, higher than in the conventional group $47.6 \%$ $(\mathrm{p}<0.05)$. The mean hospital stay in the minimal group $(10.1 \pm 2.26)$ was significantly shorter than in the conventional group (16.1 \pm 6.81$)$. (Table 1 e 2$)$

There was no significant difference in operation time between both groups. The patients in the minimal group had less blood loss $(383.3 \pm 229.86)$ than in the conventional group (90.0 \pm 11.18$)$. There was no significant difference between the two groups of preoperative VAS scores. VAS scores in the minimal group at discharge were better than in the conventional group. But in the long term, there was no difference after the 1-month follow-up. (Fig. 1)

Among 9 patients who underwent minimally invasive surgery, 5 had abscesses, 1 had a deformity, 2 had nerve deficit, and there were no spinal instability cases. Among 21 patients who underwent conventional surgery, 11 had abscesses, 8 had deformities, 12 had nerve deficits, and 10 had spinal instability. Minimally invasive surgery and conventional surgery were both available for patients with abscesses, deformities, and nerve deficit; conventional surgery was not the only option. According to the Fisher exact test, there were significant differences between both cases of spinal instability. For patients with spinal instability, we chose to use pedicle screw fixation. (Fig 2)

The mean preoperative C-reaction protein in the minimal group $(28.9 \pm 7.47)$ was lower than in the conventional group (45.1 \pm 15.78$)$. There was no significant difference between discharge and 1-month postoperative. There was no significant difference in ESR between both groups either. ESR and C-reactive protein decreased gradually during the follow-up. (Table 3)

VAS scores, C-reactive protein, and erythrocyte sedimentation rate were selected as indications to evaluate the surgical effectiveness in the group that

TABLE 1. GENERAL CONDITION OF 30 PATIENTS WITH THORACIC INFECTIONS

\begin{tabular}{l|l|l|l|l} 
& $\begin{array}{l}\text { Minimal } \\
\text { group }(n=9)\end{array}$ & $\begin{array}{l}\text { Conventional } \\
\text { group }(n=21)\end{array}$ & Statistical analysis & P value \\
\hline Age(yrs) & $66.7 \pm 9.51$ & $63.4 \pm 12.22$ & Mann-Whitney test & $0.504(p>0.05)$ \\
\hline Female $n(\%)$ & $5(55.6)$ & $9(42.9)$ & Fisher exact test & $0.694(p>0.05)$ \\
\hline Smoking $n(\%)$ & $2(22.2 T)$ & $7(33.3)$ & Fisher exact test & $0.681(p>0.05)$ \\
\hline Comorbidities $n(\%)$ & $8(88.9)$ & $10(47.6)$ & Fisher exact test & $0.049(p<0.05)$ \\
\hline Hospital stay (days) & $10.1 \pm 2.26$ & $16.1 \pm 6.81$ & Mann-Whitney test & $0.001(p<0.05)$ \\
\hline
\end{tabular}

TABLE 2. OPERATIVE INDEX

\begin{tabular}{l|l|l|l|l} 
& $\begin{array}{l}\text { Minimal group } \\
(n=9)\end{array}$ & $\begin{array}{l}\text { Conventional } \\
\text { group }(n=21)\end{array}$ & Statistical analysis & $P$ value \\
\hline Operation time $(h)$ & $2.6 \pm 0.63$ & $2.9 \pm 0.68$ & Mann-Whitney test & $0.811(p>0.05)$ \\
\hline Bleeding volume $(\mathrm{ml})$ & $383.3 \pm 229.86$ & $90.0 \pm 11.18$ & Mann-Whitney test & $0.000(p<0.05)$ \\
\hline VAS scores preoperative & $5.0 \pm 1.80$ & $5.4 \pm 1.08$ & Mann-Whitney test & $0.594(p>0.05)$ \\
\hline VAS scores at discharge & $2.9 \pm 0.93$ & $3.9 \pm 0.91$ & Mann-Whitney test & $0.028(p<0.05)$ \\
\hline VAS scores 1 month postoperative & $1.6 \pm 0.53$ & $1.4 \pm 1.03$ & Mann-Whitney test & $0.504(p>0.05)$ \\
\hline
\end{tabular}


TABLE 3. PREOPERATIVE AND 1-MONTH POSTOPERATIVE FOLLOW-UP VAS, CRP AND ESR

\begin{tabular}{|c|c|c|c|c|c|c|}
\hline \multirow[t]{2}{*}{ Case No. } & \multicolumn{2}{|l|}{ VAS } & \multicolumn{2}{|c|}{ CRP (mg/L) } & \multicolumn{2}{|c|}{$\operatorname{ESR}(\mathrm{mm} / \mathrm{hr})$} \\
\hline & Preop & $\begin{array}{l}\text { 1-month } \\
\text { Follow-Up }\end{array}$ & Preop & $\begin{array}{l}\text { 1-month } \\
\text { Follow-Up }\end{array}$ & Preop & $\begin{array}{l}\text { 1-month } \\
\text { Follow-Up }\end{array}$ \\
\hline 1 & 6 & 4 & 30.0 & 6.6 & 50 & 25 \\
\hline 2 & 5 & 3 & 25.5 & 5.6 & 47 & 12 \\
\hline 3 & 6 & 3 & 40.1 & 8.4 & 51 & 13 \\
\hline 4 & 4 & 3 & 17.4 & 2.9 & 33 & 6 \\
\hline 5 & 5 & 3 & 28.8 & 6.4 & 44 & 11 \\
\hline 6 & 3 & 2 & 21.6 & 11.3 & 30 & 7 \\
\hline 7 & 8 & 4 & 38.6 & 7.6 & 60 & 15 \\
\hline 8 & 2 & 1 & 25.4 & 3.0 & 40 & 8 \\
\hline 9 & 6 & 3 & 32.9 & 5.9 & 62 & 16 \\
\hline Mean \pm SD & $5.0 \pm 1.80$ & $2.9 \pm 0.93$ & $28.9 \pm 7.47$ & $6.4 \pm 2.60$ & $46.3 \pm 10.94$ & $12.6 \pm 5.81$ \\
\hline Wilcoxon test, $P$ value & \multicolumn{2}{|c|}{$0.007(p<0.05)$} & \multicolumn{2}{|c|}{$0.008(p<0.05)$} & \multicolumn{2}{|c|}{$0.008(p<0.05)$} \\
\hline
\end{tabular}

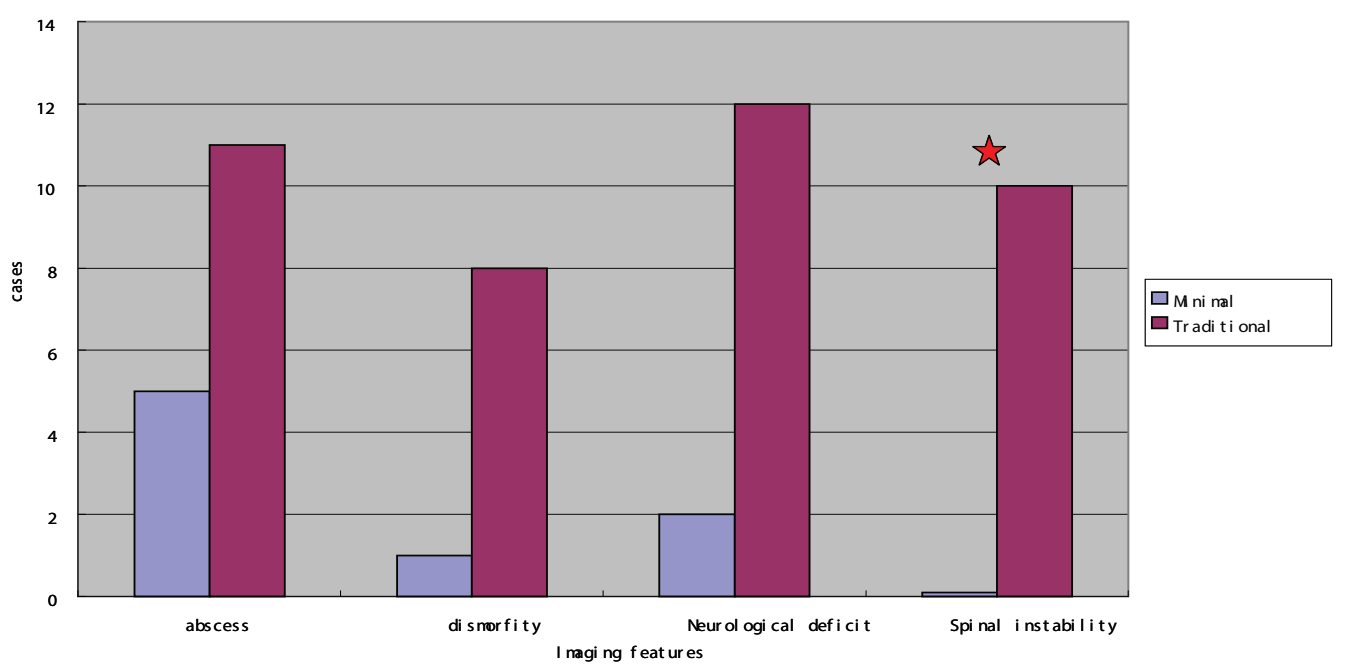

FIG.1. Comparison of imaging characteristics between the minimal and conventional group.
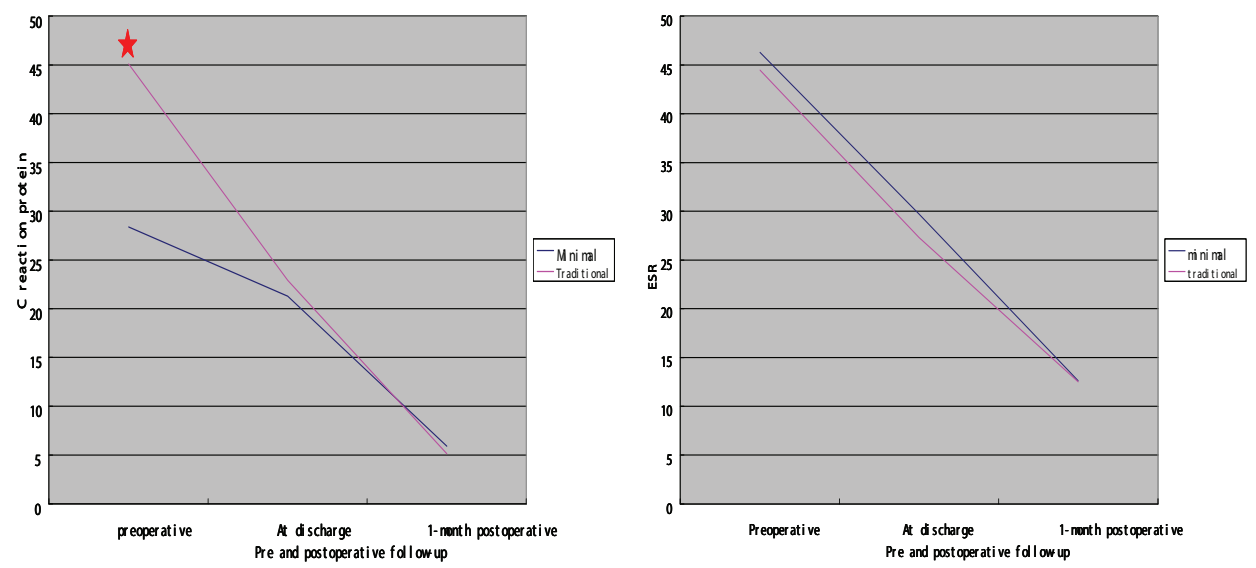

FIG.2. Preoperative, at discharge and 1-month postoperative follow-up C-reactive protein and erythrocyte sedimentation rate. 


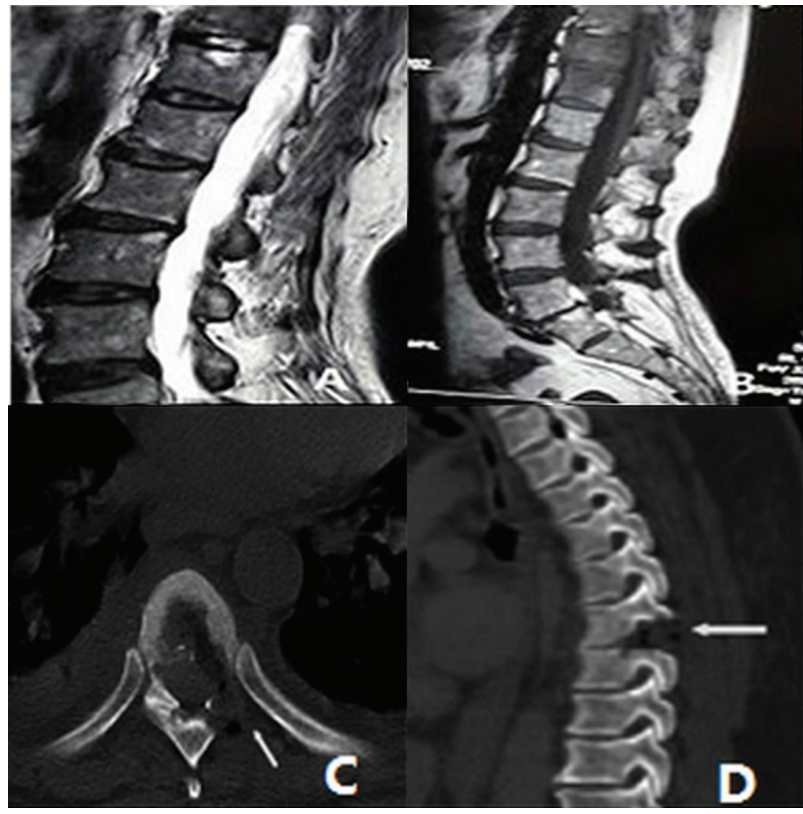

FIG.3. Preoperative and postoperative radiological images of patients.

underwent minimally invasive surgery. According to the Wilcoxon tests, there were significant differences between the preoperative and 1-month postoperative in three indexes. The VAS scores were lower, and inflammatory indexes were decreased; they were all improved. (Fig 3)

\section{DISCUSSION}

Conventional surgical treatments of thoracic infection are often accompanied by trauma and risk, which result in soft tissue injury, more bleeding, infection of peripheral structures, and slow recovery ${ }^{4}$. It is necessary to have a median incision from the posterior approach, the paraspinal muscle is stripped or injured, part of the lamina or articular process is resected, and the vertebral canal is decompressed. So many structures are affected that patients need long-term bed rest and rehabilitation exercises. The incidence of perioperative complications, such as thrombus, pneumonia, bedsore and infection is higher ${ }^{5}$. On the other hand, open surgery allows complete debridement, reconstruction, and stabilization of the thoracolumbar spine and is more suitable for patients with deformity and instability. Soft tissues are eroded by inflammatory substances and the local structure is poorly differentiated; a scar is formed in the operation area, and local anatomy is not very clear ${ }^{6}$. If treated improperly, it is easy to damage the surrounding structures. Some scholars are inclined to open surgery to avoid injury of important blood vessels and nerves. It is not suggested that open surgery is safer and minimal surgery is riskier. The choice of treatment depends on the technology available and the experience of the surgeons. Most people are not familiar with the minimally invasive approach of the thoracic spine, which causes the percutaneous endoscope not to be widely used.

Minimally invasive surgery has the advantages of minimal invasion, safety, and low cost, and it is easily accepted by patients ${ }^{7}$. Most patients want to solve the problem in one stage and prefer early ambulation. Open surgery sometimes requires preoperative biopsy and two stages: one for the posterior approach and another for the anterior approach ${ }^{8}$. The treatment process is long and complex for patients to endure. With the development of the minimally invasive technique, treating the patients safely and effectively has become a new direction ${ }^{9}$. However, we must be aware that it is not appropriate for everyone. It is better suited for patients with abscess and granulation, but it is not a good option for deformity and instability, so operation indications must be followed.

The percutaneous endoscope covers the shortage of CT guided biopsy and open surgery and is carried out to achieve the purpose of direct observation on lesions, taking out more pathogenic specimens, intervertebral disc and abscess cleaning, lavage and drainage $^{3}$. It is safe and accurate, avoiding damage to spinal stability. Compared to CT guided biopsy, more pathogenic specimens are taken out to enhance the bioptic positive rate, in order to identify pathogen types. So, it simultaneously has two functions, examination and treatment. The surgery is accomplished in a single stage, so it is easily accepted by patients ${ }^{10}$. Conventional surgery usually requires preoperative biopsy and can be divided into more stages, anterior and posterior approach. The percutaneous endoscope is not as complicated, it is finished in one stage. For patients with severe underlying diseases, diabetes mellitus, coronary heart disease, and cerebrovascular diseases, and for patients who cannot tolerate major operations and need early mobilization, minimally invasive surgery is becoming the only option. It requires less time and causes less injury, with reduced effects on the heart, blood vessels, and lung and lower complication rates. The local anesthesia adopted can achieve quick recovery after surgery without the need to enter 
the ICU ${ }^{11}$. The incidence of hypostatic pneumonia and thrombosis is obviously reduced.

There were few reports on the treatment of thoracic lesions by the transforaminal endoscope. It is a high risk that may cause damage to the spinal cord and pleura. The most critical step is the puncture. Affected by thoracic chest and ribs, the posterolateral approach is limited ${ }^{12}$. Compared with the lower lumbar spine, the puncture point is closer to the midline. The route is from $8-9 \mathrm{~cm}$ laterally to the midline, through the intervertebral foramen, towards the vertebral disc. The angle should be more inclined to the ventral side, with 40 to 45 degrees to the coronal surface and parallel with the intervertebral space, so as to keep away from important structures, such as the thoracic cavity, rib, nerve root, and spinal $\operatorname{cord}^{13}$. It is conducted under X-ray guidance during its whole course. The thoracic spinal canal has little space reserved, and blood supply and tolerance of the thoracic spinal cord are poor. Any slight injury and disturbance may lead to irreversible injury of the spinal cord. Therefore, the movements should be slow and gentle to avoid sudden damage to the spinal cord. During this period, the activities of the lower extremities are closely observed.

Since infection frequently invades the anterior column of the vertebrae, the lamina and spinal canal are usually preserved, except for epidural abscess. Nerve deficit requires decompression of the spinal cord, including removal of the lamina and articular process, and complete removal of abscess and inflammatory granulation tissues. Epidural abscess is rare, but paravertebral and anterior vertebral abscesses are common. For patients with abscess, minimally invasive surgery has more advantages, because it can clean up necrotic substances and relieve pain symptoms.

Deformity and instability result from illness progression, and open surgery is required for correction and reconstruction. A pedicle screw was used extensively because of its strong intensity, so that the three columns can be firmly fixed ${ }^{14}$. The correction of kyphosis can be achieved by compression and distraction techniques. The technique of percutaneous endoscope cannot achieve the purpose of screw implantation and correction of deformities.

Before bacterial culture and drug sensitivity, anti- biotics are empirically administrated. For gram-positive bacteria, especially methicillin-resistant Staphylococcus MRSA, vancomycin is more frequently used $^{15}$. Cefoperazone or imipenem are chosen for gram-negative bacteria, tetracycline for Brucella, isoniazid and streptomycin for tuberculosis ${ }^{16}$. After the operation, appropriate antibiotics are selected according to the results of bacterial culture and drug sensitivity ${ }^{17}$. The application of antibiotics leads to a decrease of positive rate. Three days before the operation, it is suggested to stop antibiotics so as to improve the detection ratio of microorganisms ${ }^{18}$. Mycobacterium tuberculosis has a long culture cycle and low detection rate, and mostly relies on bacterial smears, acid-fast staining and pathology, Brucella relies on immunological examination ${ }^{19}$. Systemic administration may not achieve the aim of microbiological eradication, and irrigation with antibiotics effectively kills bacteria and prevents bacterial residue. Past opinions have suggested that local agents could produce drug-resistant strains, but that has not been observed. Irrigation can increase drug concentration in the lesions, especially for low concentration resistant pathogens.

Minimally invasive surgery still has risks of complications, paralysis caused by puncture injury of the nerve root and dural, hematoma caused by blood vessel injury, pneumothorax, intestinal fistula, and so on. Surrounding structure injured by puncture is an important cause of complications. Correct selection of surgical approach and avoiding puncture injury is the key to reduce complications. The range of vision under the endoscope is narrow, so surgeons should be familiar with microscopic anatomy and avoid blindfolded operation, hemostasis thoroughly and keep the drainage regularly so as to prevent hematoma and compression of spinal cord.

\section{CONCLUSION}

Percutaneous endoscopic debridement and irrigation for thoracic infection can reduce surgical trauma and shorten operation time and is especially suitable for patients with basic diseases and poor general conditions. It is an important supplement for the conventional treatment for thoracic infection, worthy of application. 


\section{RESUMO}

OBJETIVOS: Investigar a eficácia e segurança de desbridamento endoscópico percutâneo e irrigação torácica para infecções e fazer uma escolha adequada de acordo com a condição do paciente.

MÉTODOS: Trinta pacientes com infecção torácica que receberam tratamento cirúrgico de agosto de 2014 a dezembro de 2016 foram analisados retrospectivamente. Havia 16 homens e 14 mulheres, de 41 a 90 anos, com uma média de 64,4 anos. Nove casos foram tratados com desbridamento endoscópico percutâneo e irrigação (grupo mínimo) e 21 casos foram tratados com desbridamento aberto em combinação com fixação do parafuso pedicular (grupo convencional). Os pacientes foram submetidos a acompanhamento durante um mês. Estado geral, índice operacional, resultados de laboratório e imagem e funcionalidades foram gravados.

RESULTADOS: Em comparação com o grupo convencional, há mais comorbidades em pacientes do grupo mínimo (8 casos no grupo mínimo, 10 casos no grupo convencional, $P=0,049)$, menos tempo no hospital (10,1 +2,26 dias no grupo mínimo, 16,1 + 6,81 dias no grupo convencional, $P=0,016)$, menos volume de sangramento $(383,3+229,86 \mathrm{ml}$ no grupo mínimo, $90+11,18 \mathrm{ml}$ no grupo convencional, $P$ = 0,000), menor pontuação no VAS a quitação (2,9 + 0,93 no grupo mínimo, 3,9 + 0,91 no grupo convencional, $P=0,013)$. Não houve nenhum caso de instabilidade espinhal no grupo mínimo, e 10 casos no grupo convencional, $P=0,013$. Houve diferenças significativas.

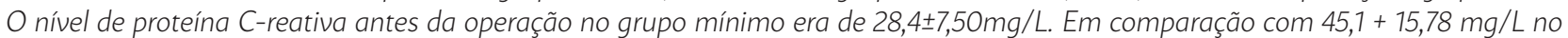
grupo convencional, $P=0,005$, era mais baixa.

CONCLUSÃo: O método de desbridamento endoscópico percutâneo e irrigação é eficaz para o tratamento de infecções em cirurgia torácica, especialmente adequado para pacientes com comorbidades e mau estado geral. Mas, para a infecção grave e instabilidade vertebral, tendemos a escolher a cirurgia aberta em combinação com a fixação.

PALAVRAS-CHAVE: Desbridamento. Endoscopia/métodos. Infecção.

\section{REFERENCES}

1. Blizzard DJ, Hills CP, Isaacs RE, Brown CR. Extreme lateral interbody fusion with posterior instrumentation for spondylodiscitis. I Clin Neurosci. 2015;22(11):1758-61.

2. Patel NB, Dodd ZH, Voorhies I, Horn EM. Minimally invasive lateral transpsoas approach for spinal discitis and osteomyelitis. J Clin Neurosci. 2015;22(11):1753-7.

3. Turel MK, Kerolus M, Deutsch $H$. The role of minimally invasive spine surgery in the management of pyogenic spinal discitis. I Craniovertebr Junction Spine. 2017;8(1):39-43.

4. Ahmadian A, Deukmedjian AR, Abel N, Dakwar E, Uribe JS. Analysis of lumbar plexopathies and nerve injury after lateral retroperitoneal transpsoas approach: diagnostic standardization. I Neurosurg Spine. 2013;18(3):289-97.

5. Lin Y, Li F, Chen W, Zeng H, Chen A, Xiong W. Single-level lumbar pyogenic spondylodiscitis treated with mini-open anterior debridement and fusion in combination with posterior percutaneous fixation via a modified anterior lumbar interbody fusion approach. | Neurosurg Spine. 2015;23(6):747-53.

6. Tschoeke SK, Kayser R, Gulow J, Hoeh Nv, Salis-Soglio Gv, Heyde C. Single-stage epidural catheter lavage with posterior spondylodesis in lumbar pyogenic spondylodiscitis with multilevel epidural abscess formation. Neurol Surg A Cent Eur Neurosurg. 2014;75(6):447-52.

7. Kim YM, Choi SM. Posterior only approach for lumbar pyogenic spondylitis with short instrumentation and prolonged suction drainage. Spine (Phila Pa 1976). 2016;41(17):E1022-9.

8. Mückley $T$, Schütz T, Schmidt MH, Potulski M, Bühren V, Beisse R. The role of thoracoscopic spinal surgery in the management of pyogenic vertebral osteomyelitis. Spine (Phila Pa 1976). 2004;29(11):E227-33.

9. Ito $M$, Abumi $K$, Kotani $Y$, Kadoya $K$, Minami A. Clinical outcome of posterolateral endoscopic surgery for pyogenic spondylodiscitis: results of 15 patients with serious comorbid conditions. Spine (Phila Pa 1976). 2007;32(2):200-6
10. Hsu LC, Tseng TM, Yang SC, Chen HS, Yen CY, Tu YK. Bilateral porta percutaneous endoscopic debridement and lavage for lumbar pyogenic spondylitis. Orthopedics. 2015;38(10):e856-63.

11. Yang SC, Chen WJ, Chen HS, Kao YH, Yu SW, Tu YK. Extended indications of percutaneous endoscopic lavage and drainage for the treatment of lumbar infectious spondylitis. Eur Spine |. 2014;23(4):846-53.

12. Guerado E, Cerván AM. Surgical treatment of spondylodiscitis. An update. Int Orthop. 2012;36(2):413-20.

13. Quesnele J, Dufton J, Stern P. Spinal infection: a case report. J Can Chiropr Assoc. 2012;56(3):209-15.

14. Fukuda K, Miyamoto H, Uno K, Okada Y. Indications and limitations of conservative treatment for pyogenic spondylitis. J Spinal Disord Tech. 2014;27(6):316-20.

15. Shiban E, Janssen I, Wostrack M, Krieg SM, Horanin M, Stoffel M, et al. Spondylodiscitis by drug-multiresistant bacteria: a single-center experience of 25 cases. Spine |. 2014;14(12):2826-34.

16. Kim C), Kang SJ, Choe PG, Park WB, Jang HC, Jung SI, et al. Which tissues are best for microbiological diagnosis in patients with pyogenic vertebral osteomyelitis undergoing needle biopsy? Clin Microbiol Infect. 2015;21(10):931-5

17. Skaf GS, Domloj NT, Fehlings MG, Bouclaous CH, Sabbagh AS, Kanafani ZA, et al. Pyogenic spondylodiscitis: an overview. J Infect Public Health. 2010;3(1):5-16.

18. Luzzati R, Giacomazzi D, Danzi MC, Tacconi L, Concia E, Vento S. Diagnosis, management and outcome of clinically- suspected spinal infection. J Infect. 2009;58(4):259-65.

19. Lee DG, Park KB, Kang DH, Hwang SH, Jung JM, Han JW. A clinical analysis of surgical treatment for spontaneous spinal infection. J Korean Neurosurg Soc. 2007;42(4):317-25. 